\title{
The Colors of Mixtures of Dental Opaque Porcelains
}

\author{
J.M. WHITE and W.J. O'BRIEN
}

Department of Restorative Dentistry, School of Dentistry, University of California, San Francisco, California 94143; and 'Department of Biologic and Materials Sciences, School of Dentistry, The University of Michigan, Ann Arbor, Michigan 48109

The colors of mixtures of dental opaque porcelains and modifiers were measured with use of the CIE $L^{*} a * b *$ uniform color space. Mixtures of dental porcelains were tested to duplicate the range of human tooth colors. Ventical movements in the yellow and blue directions were obtained. Horizontal movements in the red and green directions were achieved. Reflectance measurements were made with use of a spectrophotometer with an integrating sphere. Spectrophotometer measurements were converted to absolute reflectance and then used to calculate CIE $a^{*} b^{*}$ values for a $2^{\circ}$ standard observer and for illuminant $C$. Movements in the yellow, red, blue, and green directions for adequate simulation of the tooth color range can be demonstrated with use of dental opaque and modifier porcelains.

J Dent Res 68(9):1319-1322, September, 1989

\section{Introduction.}

The Commission Internationale de l'Eclairage developed a system for relating tristimulus values to a uniform color space (CIE, 1978). Sproull (1973a) and Lemire and Burk (1975) reported the color range of extracted teeth using $a^{*} b^{*}$ uniform color space. The color range for natural teeth lies in the yellow and red area. Studies by Culpepper (1970) and Sproull (1973b) indicate that commercial dental porcelains do not adequately cover the tooth color space. Deficiencies in the yellow and red directions exist in dental porcelain products. Moreover, in a review article, Preston (1985) described shade guides that do not uniformly cover the tooth color space. Since dental porcelains are supplied to match these shade guides, they are also limited in their color range. The objective of this research was to determine the range of colors that could be obtained by adding color modifier porcelains to the pre-mixed opaque porcelain shades.

\section{Materials and methods.}

We examined dental opaque porcelains $A_{1}, A_{2}, A_{3}, A_{3.5}, A_{4}$, $\mathrm{B}_{1}, \mathrm{~B}_{2}, \mathrm{~B}_{3}, \mathrm{~B}_{4}, \mathrm{C}_{1}, \mathrm{C}_{2}, \mathrm{C}_{3}, \mathrm{C}_{4}, \mathrm{D}_{2}, \mathrm{D}_{3}$, and $\mathrm{D}_{4}$ (Ceramco II); complex modifiers 12,13 , and 14 (Paint-O-Pake); and modifiers yellow, pink, orange, gray, and neutral (New Hue) (Johnson \& Johnson Co., East Windsor, NJ). One opaque for each shade designation (i.e., $\mathrm{A}_{1}, \mathrm{~B}_{2}$, etc.) was used so that batchto-batch variations would be avoided. Mixtures of opaque porcelains were prepared in ratios of $1: 1,2: 1,3: 1$, and $1: 1: 1$. The components of the mixtures studied are listed in Table 1 . The selected mixtures were combined, placed in a sealed test tube, and labeled. The powders were then rotated for $24 \mathrm{~h}$ in a lapidary tumbler (Lortone Division of Carborundum, Seattle, WA).

Received for publication December 12, 1988

Accepted for publication May 8, 1989

Based in part on a thesis submitted in partial fulfillment of the requirements for the Master of Science degree (Dental Materials) at the University of Michigan

This study was supported in part by National Research Service Award DE-07057 and National Institute of Dental Research grants DE-62731-18 and DE-05423.
TABLE 1

COMPONENTS AND RATIOS OF MIXTURES OF OPAQUE PORCELAINS AND MODIFIERS STUDIED

\begin{tabular}{lllllll}
\hline \hline $\mathrm{Y}$ & $1: 1$ & $\mathrm{~B}_{4}$ & $\mathrm{D}_{4}$ & $1: 1$ & $\mathrm{C}_{2}$ & \\
$\mathrm{Y}$ & $1: 1$ & $\mathrm{~B}_{3}$ & $\mathrm{O}$ & $1: 1$ & $\mathrm{~B}_{4}$ & \\
$\mathrm{Y}$ & $1: 2$ & $\mathrm{D}_{4}$ & $\mathrm{~B}_{4}$ & $1: 1$ & $\mathrm{~A}_{3.5}$ & \\
$\mathrm{Y}$ & $1: 2$ & $\mathrm{C}_{2}$ & $\mathrm{~B}_{2}$ & $1: 1$ & $\mathrm{O}$ & \\
$\mathrm{Y}$ & $1: 3$ & $\mathrm{C}_{1}$ & $\mathrm{~A}_{3.5}$ & $1: 1$ & $\mathrm{O}$ & \\
$\mathrm{B}_{1}$ & $1: 1$ & $\mathrm{~N}$ & $\mathrm{O}$ & $1: 1$ & 14 & \\
$\mathrm{~A}_{2}$ & $1: 1$ & $\mathrm{~N}$ & 12 & $1: 1$ & $\mathrm{~A}_{4}$ & \\
$\mathrm{Y}$ & $1: 1$ & 13 & 14 & $1: 1$ & $\mathrm{~A}_{3.5}$ & \\
$\mathrm{O}$ & $1: 1$ & 13 & 13 & $1: 1$ & $\mathrm{~A}_{3.5}$ & \\
$\mathrm{O}$ & $1: 1$ & 12 & $\mathrm{~B}_{4}$ & $1: 1$ & $\mathrm{D}_{3}$ & \\
$\mathrm{~B}_{4}$ & $1: 1$ & $\mathrm{D}_{3}$ & $\mathrm{~B}_{3}$ & $1: 1$ & $\mathrm{C}_{3}$ & \\
$\mathrm{~B}_{4}$ & $3: 1$ & $\mathrm{D}_{3}$ & $\mathrm{~B}_{4}$ & $1: 1$ & $\mathrm{~A}_{3}$ & \\
12 & $1: 1$ & 14 & $\mathrm{~B}_{4}$ & $2: 1$ & $\mathrm{~A}_{3}$ & \\
$\mathrm{~B}_{3}$ & $1: 1$ & $\mathrm{C}_{3}$ & $\mathrm{~B}_{4}$ & $3: 1$ & $\mathrm{~A}_{3}$ & \\
$\mathrm{~B}_{3}$ & $1: 1$ & $\mathrm{C}_{3}$ & 13 & $1: 1$ & 14 & \\
13 & $2: 1$ & 14 & $\mathrm{D}_{4}$ & $1: 1$ & $\mathrm{~A}_{3.5}$ & \\
$\mathrm{Y}$ & $2: 1$ & 13 & $\mathrm{D}_{4}$ & $2: 1$ & $\mathrm{~A}_{3.5}$ & \\
$\mathrm{Y}$ & $3: 1$ & 13 & $\mathrm{~A}_{1}$ & $1: 1$ & $\mathrm{~A}_{2}$ & \\
$\mathrm{O}$ & $2: 1$ & 13 & $\mathrm{~A}_{1}$ & $2: 1$ & $\mathrm{~A}_{2}$ & \\
$\mathrm{O}$ & $3: 1$ & 13 & $\mathrm{C}_{1}$ & $1: 1$ & $\mathrm{C}_{4}$ & \\
$\mathrm{C}_{1}$ & $2: 1$ & $\mathrm{C}_{4}$ & $\mathrm{D}_{2}$ & $1: 1$ & $\mathrm{~A}_{2}$ & \\
$\mathrm{C}_{1}$ & $1: 1$ & $\mathrm{~A}_{2}$ & $\mathrm{D}_{2}$ & $1: 1$ & $\mathrm{O}$ & \\
$\mathrm{O}$ & $1: 1$ & $\mathrm{~A}_{2}$ & $\mathrm{C}_{1}$ & $1: 1$ & $\mathrm{D}_{4}$ & \\
$\mathrm{~B}_{3}$ & $1: 1$ & $\mathrm{~A}_{3}$ & 12 & $1: 1$ & 14 & \\
$\mathrm{D}_{2}$ & $1: 1$ & $\mathrm{C}_{3}$ & $\mathrm{~B}_{4}$ & $1: 1$ & $\mathrm{~A}_{3}$ & \\
& & & $\mathrm{D}_{4}$ & $1: 1$ & $\mathrm{~A}_{3.5}$ & \\
& & & $\mathrm{~B}_{1}$ & $3: 1$ & $\mathrm{P}_{2}$ & \\
& & & $\mathrm{~B}_{2}$ & $3: 1$ & $\mathrm{P}_{2}$ & \\
& & & $\mathrm{~A}_{3}$ & $3: 1$ & $\mathrm{P}$ & \\
\hline & & & $\mathrm{D}_{4}$ & $1: 1$ & $\mathrm{D}_{3}$ & $1: 1$ \\
& & & $\mathrm{~A}_{2}$ & $1: 1$ & $\mathrm{~B}_{1}$ & \\
& & & & & & \\
& & & & & \\
& & & &
\end{tabular}

Each sample was weighed and placed in a cylindrical $17-$ mm-diameter metal mold. The powders were then compacted dry at $422 \mathrm{~kg} / \mathrm{cm}^{2}$ for one min. The weighing apparatus was a Mettler E2000 (Mettler Instrument Corp., Princeton, NJ) balance, and the hydraulic press was a Drake (Drake Corp., Grand Haven, MI). The compacted samples were then placed in a Cera-Mat III (Jelrus Dental Products Corp., New Hyde Park, NY) porcelain oven that was programed for the opaque firing cycle (Table 2). The firing cycle produced a sample with an egg shell/matte surface texture. Samples were inspected visually for homogeneity and surface texture. The final dimensions of the samples were $15 \pm 0.2 \mathrm{~mm}$ (diameter) and

TABLE 2

PORCELAIN FIRING CYCLE

\begin{tabular}{ll}
\hline Low Temperature & $600^{\circ} \mathrm{C}$ \\
Pre-heat & $1.00 \mathrm{~min}$ \\
Heat Rate & $38^{\circ} \mathrm{C} / \mathrm{min}$ \\
Vacuum & on \\
Vent & $927^{\circ}-943^{\circ} \mathrm{C}$ \\
High Temperature & $1000^{\circ} \mathrm{C}$ \\
Hold Time & 2ero \\
Cool Time & $5.00 \mathrm{~min}$ \\
\hline
\end{tabular}




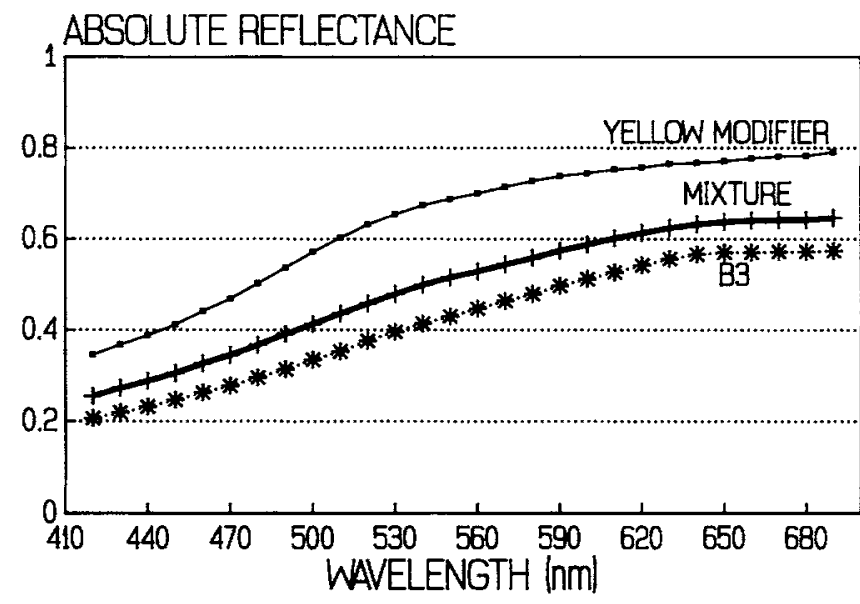

Fig. 1-Absolute reflectance of yellow modifier, $B_{3}$ opaque porcelain, and their $1: 1$ mixture in the visible light range.

$2.0 \pm 0.2 \mathrm{~mm}$ (thickness). The $2-\mathrm{mm}$ thickness provided a sample that is well beyond the infinite optical limits for opaque porcelain, precluding the need for specimen-backing.

Relative reflectance data of each sample were measured on a Beckman spectrophotometer (Acta C-III UV-visible spectrophotometer, Beckman Instruments, Irvine, CA) with an integrating sphere (ASPH-U integrating sphere, Beckman) attachment. The reflectance measurements were stored in decimal form and utilized for calculation of the CIE $\mathrm{L}^{*} \mathrm{a}^{*} \mathrm{~b}^{*}$ values with use of the parameters of a $2^{\circ}$ standard observer for illuminant $\mathrm{C}$. The spectrophotometer with an integrating sphere recorded the relative reflectance data in the visible range from 410 to $700 \mathrm{~nm}$. The interval for measurement was $10 \mathrm{~nm}$, which yielded 30 data points. For all measurements, the specular exit port was closed, including all specular reflection. The spectrophotometer utilizes direct illumination and diffuse observation. The instrument was calibrated first with a zero cone (Part Number 587738, Beckman Instruments, Irvine, CA) and then with a $\mathrm{B}_{2}$ (Erie Ceramic Arts, Erie, PA) white porcelain standard. The $B$, standard has a known absolute reflectance traceable to the National Institute of Standards and Technology. Each sample was run twice. The incident beam was approximately $0.9 \times 8 \mathrm{~mm}$. The reference sample was a barium sulfate plate that allowed maximum reflectance and uniformity with the inner coating of the sphere. Each sample was measured in reflectance, and values were stored on the system's (Michigan Terminal System) computer. All samples were measured in reflectance on the spectrophotometer.

Using the combined coordinates of Lemire and Burk (1975) and Sproull (1973a), we determined the boundaries of the natural tooth color space envelope. The test mixtures were plotted, and the movements obtained were analyzed.

\section{Results.}

A plot of absolute reflectance vs, wavelength showed the reflectance characteristics of the mixture of yellow modifier and $B_{3}$ over the range of 410 to $700 \mathrm{~nm}$ (Fig. 1). The mixture did not have the average absolute reflectance of each component porcelain. The effects of the porcelains on the mixture were not linear throughout the visible range, and the resultant color was a complex combination of the optical properties of the porcelains.

The colors of opaque porcelains and of orange, yellow, and pink modifiers in CIE $a^{*} b^{*}$ are shown in Fig. 2. The opaque

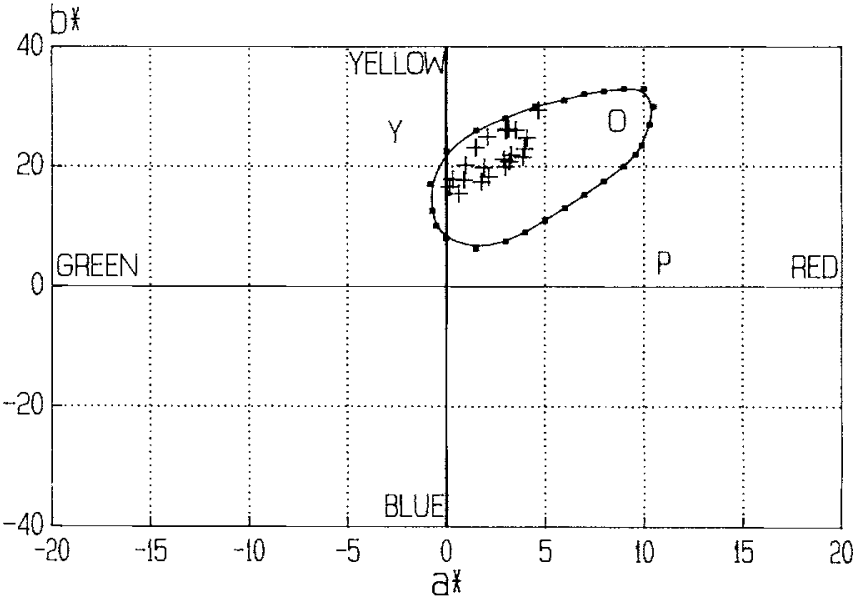

Fig. 2-CIE $a^{*} b^{*}$ color space showing maximum tooth color space, orange (O), yellow $(\mathrm{Y})$, and pink $(\mathrm{P})$ modifiers, and supplied opaque porcelains shade series $A, B, C$, and D.

porcelains were not uniformly distributed and were concentrated in the yellow area of the color space. The boundaries of the natural tooth color space indicate deficiencies in the orange, red, and blue directions, which cause a poor overlap with the natural dentition.

Fig. 3 plots all the mixtures studied. These mixtures expanded the distribution within the tooth color space. The illustration also shows the three modifiers (orange, yellow, and pink) and the opaque porcelains. The complex modifier porcelains $(12,13$, and 14) were also included. The mixtures expanded the color distribution in the orange, red, and blue directions. These mixtures extended the distribution within the tooth color space. The mixtures presented moved in the yellow, orange, and red directions and filled existing voids in the color space. The $3: 1$ and $2: 1$ mixtures shown did not move equal increments. For the $3: 1$ mixture of $C_{1}$ and yellow, the resultant $a^{*} b^{*}$ was much closer to the original $C_{1}$. To move more toward the yellow, additional amounts of modifier need to be added.

Fig. 4 illustrates three of the seven selected mixtures with the orange modifier. The orange modifier lies within the tooth

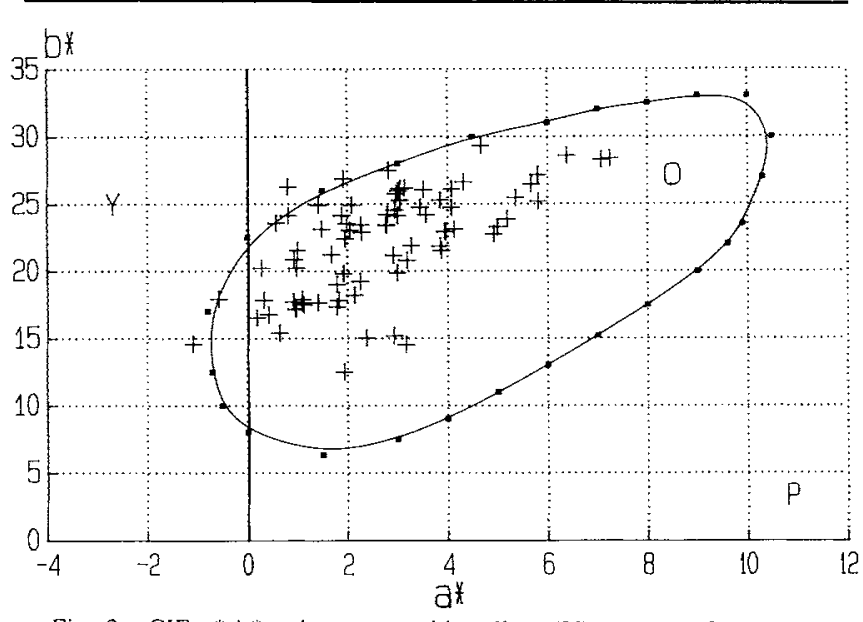

Fig. 3-CIE a* b* color space with yellow $(\mathrm{Y})$, orange (O), and pink (P) modifiers, and all test mixtures studied in the tooth color space, indicating expansion in the color space. 


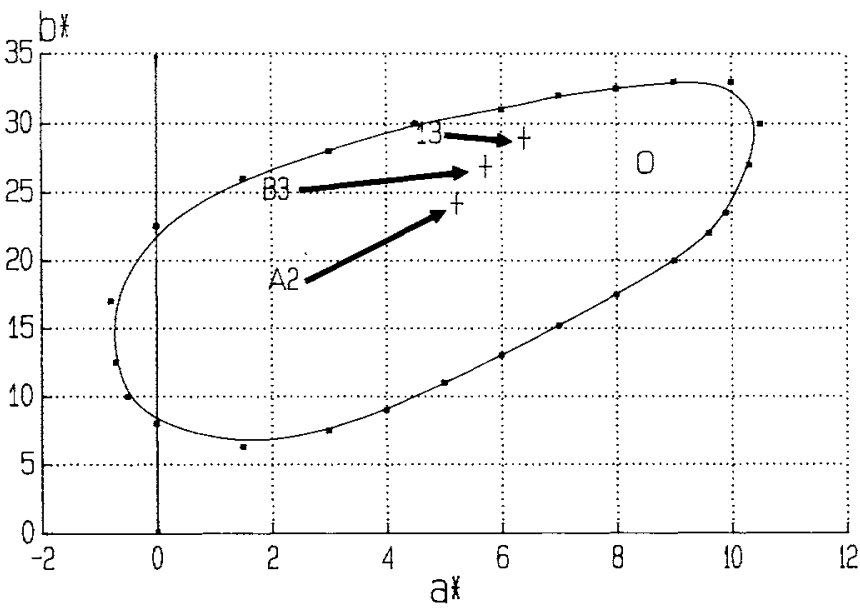

Fig. 4-Arrows illustrate the movements in the orange direction achieved by $1: 1$ mixtures of original opaque porcelains $(13, \mathrm{~B} 3, \mathrm{~A} 2)$ and orange modifier $(O)$ in the tooth color space.

color space. Mixtures with orange modifier expanded the coverage by increasing the $a^{*}$ value. The seven mixtures studied were mixtures of $13, B_{4}, B_{3}, 12,14, A_{2}$, and $A_{3.5}$ with orange modifier. These mixtures were all $1: 1$.

Fig. 5 displays three selected mixtures of opaque porcelains and the pink modifier. Each opaque was in a 3:1 ratio with the pink component. These mixtures filled a large area in the tooth color space not covered by the opaque products.

It was possible for horizontal, $\mathrm{a}^{*}$, movements to be achieved within the tooth color space (Fig. 6). These movements were in the red and green directions. A 1:1 and 2:1 mixture of $D_{4}$ and $A_{3.5}$ resulted in constant $b^{*}$ values. The mixtures obtained varied only in $a^{*}$. Similarly, $1: 1$ mixtures of $C_{1}-A_{2}$ and $C_{1}-D_{2}$ resulted in $a^{*}$ movements with nearly constant $b^{*}$.

Examples of vertical movements within the tooth color space are shown in Fig. 7. These movements were in the yellow and blue directions. For all mixtures, the $a^{*}$ value remained nearly constant. The $b^{*}$ value from the resultant mixture was plotted between the two components. The result was movements in the $b^{*}$ direction.

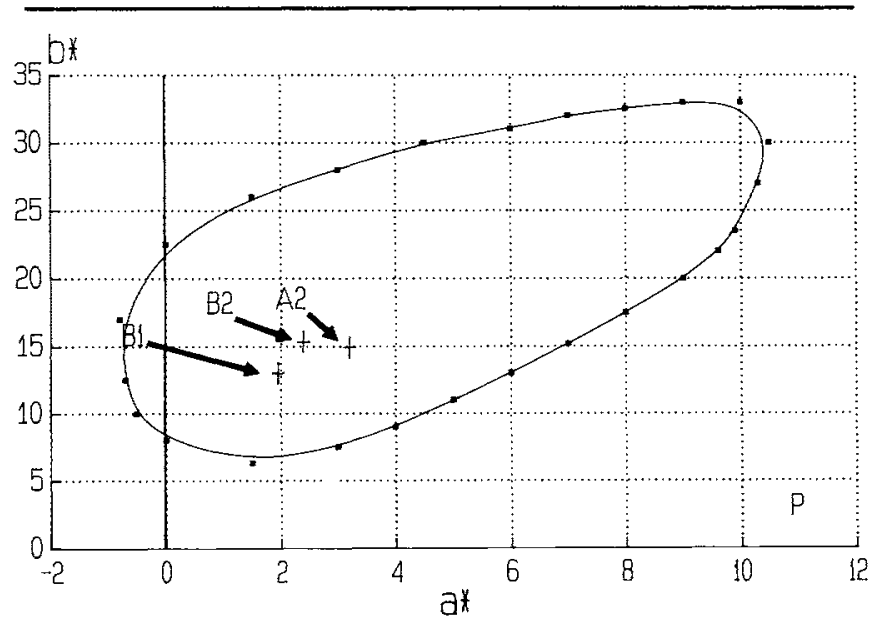

Fig. 5-Arrows indicate movements in the red direction using pink modifier $(P)$ and original opaque porcelains $A_{2}, B_{2}$, and $B_{1}$ in ratios of $1: 3$.

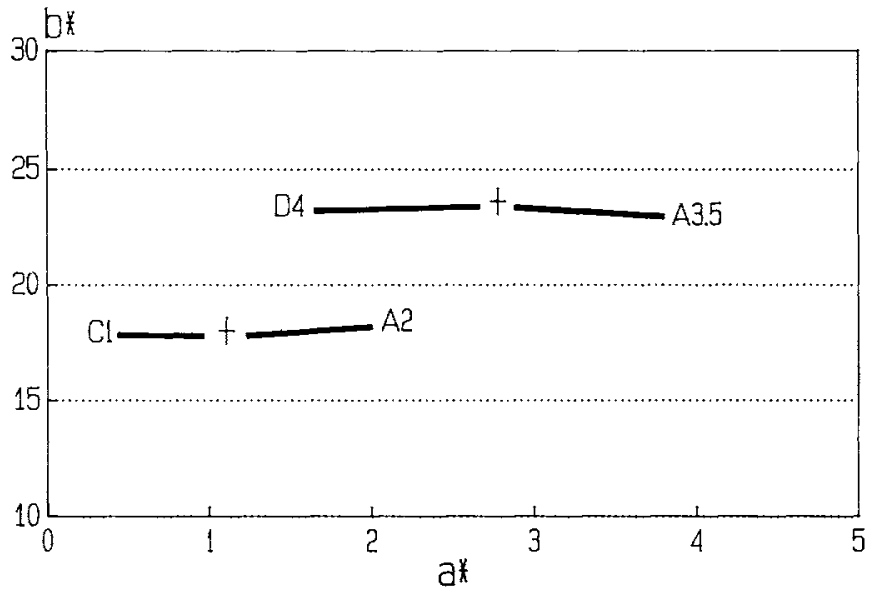

Fig. 6-Horizontal movements in the tooth color space with $1: 1 \mathrm{mix}$ tures of original porcelains, $D_{4}-A_{3.5}$, and $C_{1}-A_{2}$.

\section{Discussion.}

The appearance of a porcelain prosthesis is related to its size, shape, surface texture, translucency, and color (Judd and Wyszecki, 1975). Studies of color measurements from extracted teeth have given information on the natural tooth color space. By combining the values reported, we defined the largest area. This area of tooth color space provides a working model in which the color of opaque porcelains can be studied.

Manufacturer-supplied pre-mixed opaque porcelains do not uniformly cover the natural tooth color space. The opaque porcelains can be mixed with modifiers and with each other to extend the coverage within the color space. Movements in the yellow, pink, and orange directions can be obtained by inclusion of these modifiers. Experimentally, these movements are recorded on the CIE $L^{*} a^{*} b^{*}$ color scale with use of parameters of the $2^{\circ}$ standard observer and illuminant $\mathrm{C}$. Although the mixtures studied expand the range of porcelain coverage in the tooth color space, voids still exist. The deficient areas are in the orange and red directions. Mixtures of porcelains with yellow modifier adequately fill areas in the yellow direction not covered by the porcelain products.

Spectrophotometer instruments that use direct illumination

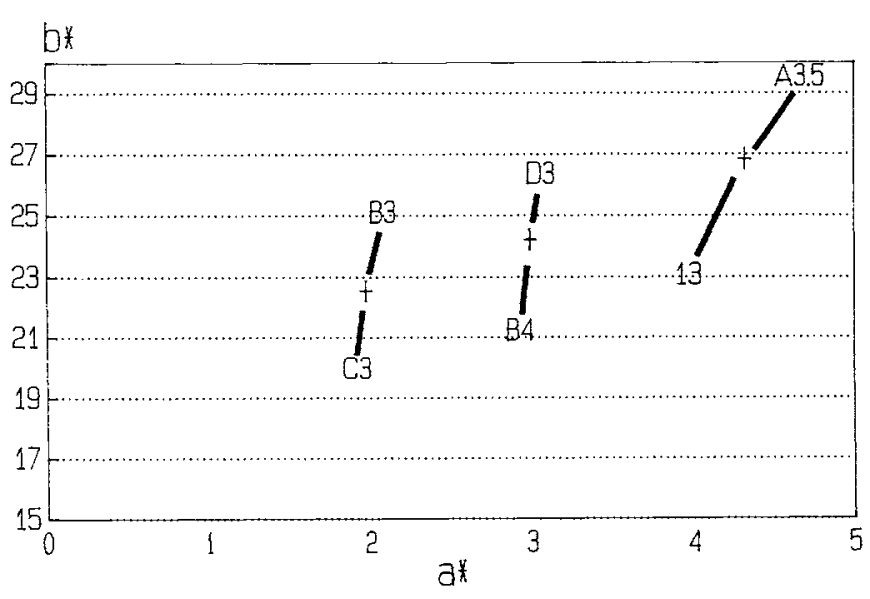

Fig. 7-Vertical movements in the tooth color space using mixtures of original opaque porcelains, $A_{3.5}-13, D_{3}-B_{4}$, and $B_{3}-C_{3}$. 
and diffuse viewing are available for measurement of color. Using this method, Johnston and O'Brien (1982) have studied modifying porcelains to assign color names with a universal language of color terms (Kelley and Judd, 1976). The absolute reflectance we obtained showed that opaque porcelain mixtures are a combination of the optical properties of the parent porcelains. Absolute reflectance was then converted to the uniform color scale. The CIE L* $a^{*} b^{*}$ color scale relates standard observer characteristics to a uniform scale where changes can be measured and analyzed. Further experimentation should include the $L^{*}$, or value of the mixtures. The gray characteristics will aid in the determination of movements in three dimensions and should further define the appearance of dental porcelains. Furthermore, the study of color movements may aid in the development of methods for the prediction of color, which may expedite the fabrication of porcelain prostheses.

As dentistry continues to define optical properties of materials, equipment will be developed to aid in the treatment of patients. Clinicians, laboratory personnel, and manufacturers can better serve the public by defining and utilizing the optical parameters in dentistry.

\section{Acknowledgments.}

We thank Teresa McGrath, Patricia Eger-Herz, and Cara Voss for their contributions to the preparation of this manu- script. We are especially indebted to Dr. William Johnston for his efforts concerning the spectrophotometer color calculation programs.

\section{REFERENCES}

C.I.E., Commission Internationale de l'Eclairage (1978): Recommendations on Uniform Color Spaces, Color Difference Equations, and Metric Color Terms, Suppl No. 2 to Pub. No. 15, Paris: Bureau Central de la CIE.

CULPEPPER, W.D. (1970): A Comparative Study of Shade-matching Procedures, $J$ Prosthet Dent 24:166-173.

JOHNSTON, W.M. and O'BRIEN, W.J. (1982): Color Analysis of Dental Modifying Porcelains, $J$ Dent Res 61:484-488.

JUDD, D.B. and WYSZECKI, G. (1975): Color in Business, Science and Industry, 3rd ed., New York, NY: Wiley, pp. 102172.

KELLEY, K.L. and JUDD, D.B. (1976): Color-Universal Language and Dictionary of Names (NBS Spec. Publ. 440), Washington, D.C.: U.S. Government Printing Office, p. 10.

LEMIRE, P.A. and BURK, B. (1975): Color in Dentistry, Bloomfield, CT: Ney Company.

PRESTON, J.D. (1985): Current Status of Shade Selection and Color Matching, Quintessence Int 16:47-58.

SPROULL, R.C. (1973a): Color Matching in Dentistry, Part I. The Three Dimensional Nature of Color, $J$ Prosthet Dent 29:416-424.

SPROULL, R.C. (1973b): Color Matching in Dentistry, Part II. Practical Applications of the Organization of Color, $J$ Prosthet Dent 29:556-566. 